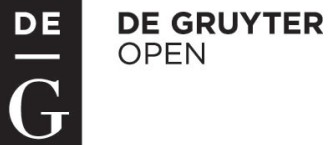

DOI: 10.1515/genst -2015-0010

\title{
GENDER AND LIFE SATISFACTION IN THE CZECH REPUBLIC
}

\author{
SANJOY KUMAR CHANDA \\ Sociology Department, Khulna University \\ Khulna 9208, Bangladesh \\ skcsoc@gmail.com
}

\begin{abstract}
Life satisfaction in its gender aspects opens up a new dimension in social research. This study starts with the research question of how life satisfaction and gender are associated with intrinsic and extrinsic aspirations. The questionnaire survey was used with 1821 respondents in the Czech Republic. The results show that it was in the 33-48 age range that the highest proportion of males, 59 per cent, expressed substantial life satisfaction, compared to the 18-32 age range for females (72 per cent). In addition, for males, a greater identification with life satisfaction is found for both intrinsic and extrinsic aspirations, whereas females represented this greater identification only in regard to intrinsic aspirations.
\end{abstract}

Keywords: Czech Republic, extrinsic, gender, intrinsic, satisfaction.

\section{Introduction}

Life satisfaction is the way a person perceives how his or her life has been and how they feel about it, where it is going in the future. It is a measure of wellbeing and may be assessed in terms of mood, satisfaction 
with relations with others and with achieved goals, self-concepts, and selfperceived ability to cope with daily life. It is having a favourable attitude to one's life as a whole rather than positive current feeling (Wikipedia 2013). Shin and Johnson define life satisfaction as "a global assessment of a person's quality of life according to his chosen criteria” (1978:478). Life satisfaction judgments therefore depend on the standards individuals have set for themselves. But perceptions of life satisfaction vary in the perspective of gender. Sometimes the variation is unidentified, intentionally or unintentionally, and this results in gender disparity. Here, therefore, we have tried to address gender differences so that inequality can be identified and policymakers can take the necessary steps to promote the highest degree of life satisfaction.

\subsection{Literature Review}

The study of life satisfaction has a tradition in social research. Changing patterns of satisfaction and their relation with the gender dimension have elicited new, inventive pedagogical responses. Different researchers have carried out a variety of studies. Beutell (2006) concludes that both nature and nurture (i.e., personality and environment) appear to be influential in determining life satisfaction, and that to discount one explanation in favor of the other would not be empirically or theoretically productive. From a different angle, Chipper and Havens (2001) conducted a study to examine life satisfaction among individuals whose marital status had remained stable over seven years and found the women's life satisfaction had declined while the men's had remained constant.

Kousha and Mohseni (1997) explored life satisfaction among married and unmarried Iranian women in urban areas. Data were analyzed 
from a sample of 335 women of whom 61 percent were married and 39 percent unmarried (i.e. single, divorced or widows). A series of path analyses and cross tabulations suggests that for married women life satisfaction is directly linked to their satisfaction with marriage, employment and their leisure experiences. Life satisfaction as related to cultural values is familismo, which emphasizes the importance of loyalty, reciprocity, and solidarity toward one’s family (Marín and Marín 1991). After the age of 75, people's life satisfaction of keeps decreasing, and those over 80 reported the lowest scores in life satisfaction (Wang 2008). Life satisfaction is modeled as a dependent variable that co-varies with factors such as political culture, the size of the welfare state, labor union density, the absence of government corruption, political freedom, and the level of democracy (Flavin and Keane 2007).

By contrast, Saundra and Hughey (2003) conducted a study on 147 African American women from six states in the USA who were asked to complete the Adult Life Satisfaction Scale and the Black Women's Spirituality/Religiosity Measure (BWSRM). No significant difference was found between the ratings of life satisfaction and those of spirituality. However, an inverse relationship was found between satisfaction and women's level of activity (Kousha and Mohseni 1997).

The above studies were conducted on life satisfaction and a range of variables related to it. Most of the studies present the relationship between life satisfaction and other factors, especially in the context of women. In addition, the studies by Saundra and Hughey (2003) and Kousha and Mohseni (1997) also depicted an inverse relationship. These studies suggest a relationship between gender and life satisfaction. Most of the variables they take into account have similarities with our proposed study. Their 
methodological interpretation and statistical analysis have provided direction for the conduct of the proposed study and the data analysis involved. It is the aim of this study to extend previous research and identify new issues by showing the correlation between intrinsic aspirations (personal) and extrinsic aspirations (impersonal) and satisfaction as between males and females.

\subsection{Theoretical Framework}

Here the following theories will be described as these are related to this study.

Self Determination Theory: Self Determination Theory (SDT) proposes that all "expectancy" models must be qualified by the content of goals. Its authors initiated a program of research to explore the distinction between intrinsic and extrinsic aspirations. They specifically hypothesized that there were significant individual differences in people's focus on intrinsic versus extrinsic aspirations. 'Intrinsic' is closely linked to the internal nature of the person whereas 'extrinsic' includes goals outside of the individual. They hypothesized that wealth and material possessions, social recognition and fame, and image or attractiveness would represent extrinsic goals. Four other aspects were thought to represent intrinsic goals: personal growth, affiliation and intimacy, contributing to one's community, and physical health (Kasser and Ryan 1996).

\subsubsection{Objective Theory of Wellbeing}

Capability Approach: The well-recognized needs-based account of

wellbeing of Sen's capabilities approach posits a framework focusing on the degree to which individuals can perform effectively with the goods that 
they have at hand. To establish framework, Sen distinguished between 'functionings' and 'capability'. 'Functionings' means the various activities that an individual may value doing, while that individual's 'capability' consists of the alternative combinations of functionings that are feasible for her to achieve (Sen 1999:75). One's capability is therefore a form of freedom, as it affords the opportunity to achieve multiple combinations of functionings. Sen identified a link between capability approach and gender, claiming that "the question of gender inequality [...] can be understood much better by comparing those things that intrinsically matter (such as functionings and capabilities), rather than just the means (to achieve them) like [...] resources. The issue of gender inequality is ultimately one of disparate freedoms"' (Sen 1992:125). So gender inequality in the space of functionings and capabilities is posited to account for human diversity, including the diversity stemming from people’s gender.

\subsection{Research Question}

Principal question: How does life satisfaction correlate with intrinsic and extrinsic aspirations as between males and females in the Czech Republic? Here a comparison is made between males and females to show whether life satisfaction varies in accordance with gender.

\section{Supporting questions:}

1. Does life satisfaction differ between male and female?

2. How does life satisfaction correlate with intrinsic aspirations between male and female?

3. How does life satisfaction correlate with extrinsic aspirations between male and female? 


\section{Methodology}

This is a quantitative study. Data from the European Value SurveyEVS 2008, collected from three different European countries including the Czech Republic, Finland and France, was used. For this study only the data from the Czech Republic was used. The total sample size from the Czech Republic was 1821. Data was collected through a field survey using an interview schedule.

The satisfaction in life variable was used in two ways: 1) interval variable where a 10 point scale is used. 1 is counted as low and 10 as high and 2) this scale was divided into three ranking orders (reverse) for explanation that included high satisfaction (8-10), medium (4-7) and low (1-3). Here high satisfaction is coded as 1 , medium satisfaction as 2 and low satisfaction as 3 .

The gender variable includes two categories, male and female. Here male is coded as 1 and female as 2. Age range is divided into four groups and coded as $18-32=1,33-48=2,49-61=3$ and $62+=4$. Differences in religious belief are divided into three categories and coded as religious believers $=1$, not religious believers $=2$ and convinced atheists $=3$. The variable 'employed' is divided into yes or no. Yes is coded as 1 and no as 2. The interval variable political view is measured on a 10 point scale where the scale is drawn from left viewed to right. Left viewed starts from the left side of the scale, ending with right viewed on the right side. The nominal variable marriage is categorized into four cases and coded as married $=1$, widower $/$ widowed $=2$, divorced $=3$ and never married $=4$. The importance of family variable has three ranking orders and is coded as very important $=1$, important $=2$ and not important $=3$. The political variable satisfaction with democracy is categorized into four ranking cases 
and coded as very satisfied $=1$, quite satisfied $=2$, not very satisfied $=3$ and not at all $=4$.

To interpret the data, both descriptive (percentage distribution and graph) and inferential statistics (compare means, chi square and correlation) were used. Both univariate and bivariate analyses were followed to interpret data. To gather and clean the data, SPSS and Excel were used. Data was analyzed for two aspirations termed intrinsic and extrinsic. 'Intrinsic' is used to identify personal aspirations while impersonal categories are related to extrinsic aspiration.

\section{Results}

\subsection{Background of Data}

\subsubsection{Level of Satisfaction}

Figure 1: Distribution of Overall Level of Life Satisfaction

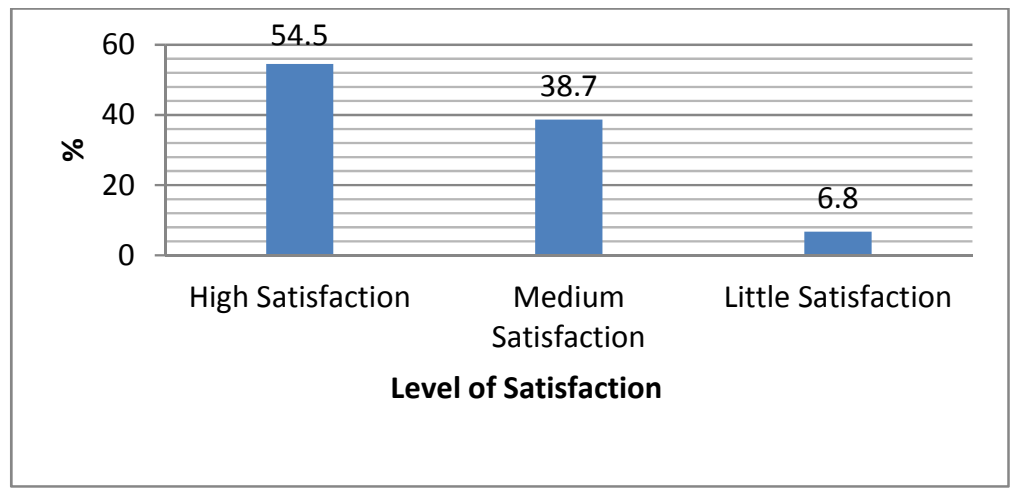

The data in figure 1 indicate that overall level of satisfaction in life in the Czech Republic may be divided into three categories: high satisfaction, medium satisfaction and little satisfaction. Overall more than half of the respondents were highly satisfied, with the following approximately 39 percent partially satisfied. Only 7 percent expressed little satisfaction with their life. 


\subsubsection{Gender}

Figure 2 shows that 51.6 percent of respondents were male and 48.4 percent female.

Figure 2: Distribution of Gender

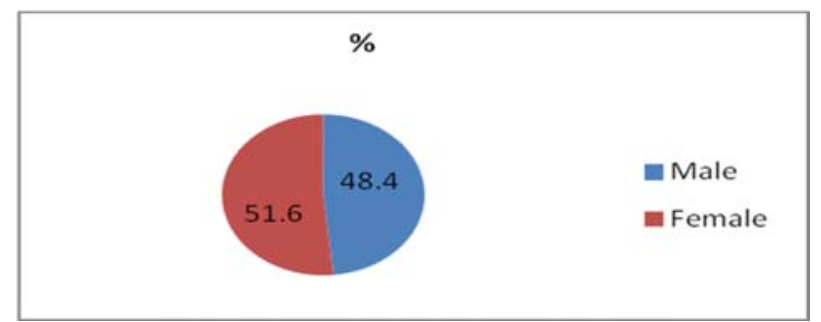

\subsection{Compare Gender in Life Satisfaction}

\subsubsection{Life Satisfaction by Gender}

Table 1: Life Satisfaction by Gender (Compare means)

\begin{tabular}{|l|c|c|c|c|}
\hline Satisfaction in Life & \multicolumn{5}{|l|}{} \\
\hline Gender & Mean & Std Deviation & $\mathrm{N}$ & \% of Total Sum \\
\hline Male & 7.14 & 2.117 & 875 & $47.9 \%$ \\
\hline Female & 7.29 & 2.079 & 932 & $52.1 \%$ \\
\hline Total & 7.21 & 2.099 & 1807 & $100.0 \%$ \\
\hline
\end{tabular}

Table 1 was created based on overall life satisfaction. Mean differences between the male and the female group give the information that females (7.29 percent) were on average more satisfied in their lives than males (7.14 percent).

\subsection{Intrinsic Aspiration}




\subsubsection{Age}

\subsubsection{Relationship between Life Satisfaction and Age Groups}

Table 2 provides comparative information about satisfaction in life by age group between males and females in the Czech Republic. In males the highest number (59 percent) of people highly satisfied in life were to be found in the 33-48 age group, while the highest number (72 percent) of highly satisfied females occurs in the 18-32 age bracket. In addition, a similarity was found for age groups of $62+$ between the two groups in the category of medium satisfaction in life where responses showed a highest level of 48 percent and 43 percent in male and female respectively. Again, the very lowest levels of satisfaction in life were identified for both males (10 percent) and females (11 percent) in the category of low satisfaction.

Table 2: Life Satisfaction by Age Groups by Gender

\begin{tabular}{|l|c|c|c|c|c|c|c|c|}
\hline \multirow{2}{*}{$\begin{array}{l}\text { Level of } \\
\text { Satisfaction }\end{array}$} & \multicolumn{9}{|c|}{ Age Groups } \\
\cline { 2 - 9 } & Gender & \multicolumn{7}{|c|}{ Male } \\
\cline { 2 - 9 } & $18-32$ & $33-48$ & $49-61$ & $62+$ & $18-32$ & $33-48$ & $49-61$ & $62+$ \\
\hline $\begin{array}{l}\text { High } \\
\text { Satisfaction }\end{array}$ & 140 & 150 & 95 & 71 & 183 & 130 & 102 & 113 \\
\hline$\%$ & 54.3 & 59.3 & 48.2 & 42.5 & 71.8 & 57.3 & 49.0 & 46.7 \\
\hline $\begin{array}{l}\text { Medium } \\
\text { Satisfaction }\end{array}$ & 104 & 86 & 86 & 80 & 68 & 84 & 89 & 103 \\
\hline$\%$ & 40.3 & 34.0 & 43.7 & 47.9 & 26.7 & 37.0 & 42.8 & 42.6 \\
\hline $\begin{array}{l}\text { Low } \\
\text { Satisfaction }\end{array}$ & 14 & 17 & 16 & 16 & 4 & 13 & 17 & 26 \\
\hline$\%$ & 5.4 & 6.7 & 8.1 & 9.6 & 1.6 & 5.7 & 8.2 & 10.7 \\
\hline Total & 258 & 253 & 197 & 167 & 255 & 227 & 208 & 242 \\
\hline$\%$ & 100.0 & 100.0 & 100.0 & 100.0 & 100.0 & 100.0 & 100.0 & 100.0 \\
\hline $\begin{array}{l}\text { Spearman } \\
\text { Correlation }\end{array}$ & Value: .096, P $<.005$ & & & & Value: .208, P <.000 \\
\hline
\end{tabular}

The Spearman correlation value of .096 for male with $\mathrm{P}<.005$ (P means probability) and .208 with $\mathrm{P}<.000$ for female indicates a positive 
relationship between satisfaction in life and age group. Though the associations are not particularly high for either male or female (the values are not so close to 1 ), the association for female is higher than for male. The statistics demonstrate that satisfaction in life varies between different age groups.

\subsubsection{Religion}

Table 3: Life Satisfaction by Religious Belief and Gender

\begin{tabular}{|c|c|c|c|c|c|c|}
\hline \multirow{4}{*}{$\begin{array}{l}\text { Level of } \\
\text { Satisfaction }\end{array}$} & \multicolumn{6}{|c|}{ Religious Believes } \\
\hline & \multicolumn{6}{|l|}{ Gender } \\
\hline & \multicolumn{3}{|c|}{ Male } & \multicolumn{3}{|c|}{ Female } \\
\hline & $\begin{array}{c}\text { Religious } \\
\text { Believer }\end{array}$ & $\begin{array}{c}\text { Not Religious } \\
\text { Believer }\end{array}$ & $\begin{array}{l}\text { Convinced } \\
\text { Atheist }\end{array}$ & $\begin{array}{c}\text { Religious } \\
\text { Believer }\end{array}$ & $\begin{array}{c}\text { Not } \\
\text { Religious } \\
\text { Believer }\end{array}$ & $\begin{array}{l}\text { Convinced } \\
\text { Atheist }\end{array}$ \\
\hline $\begin{array}{l}\text { High } \\
\text { Satisfaction }\end{array}$ & 105 & 232 & 88 & 190 & 247 & 55 \\
\hline$\%$ & 53.0 & 52.1 & 52.1 & 55.1 & 60.1 & 51.4 \\
\hline $\begin{array}{l}\text { Medium } \\
\text { Satisfaction }\end{array}$ & 71 & 180 & 75 & 127 & 148 & 44 \\
\hline$\%$ & 35.9 & 40.4 & 44.4 & 36.8 & 36.0 & 41.1 \\
\hline $\begin{array}{l}\text { Low } \\
\text { Satisfaction }\end{array}$ & 22 & 33 & 6 & 28 & 16 & 8 \\
\hline$\%$ & 11.1 & 7.4 & 3.6 & 8.1 & 3.9 & 7.5 \\
\hline Total & 198 & 445 & 169 & 345 & 411 & 107 \\
\hline$\%$ & 100.0 & 100.0 & 100.0 & 100.0 & 100.0 & 100.0 \\
\hline $\begin{array}{l}\text { Spearman } \\
\text { Correlation }\end{array}$ & \multicolumn{3}{|c|}{ Value: -.017, $\mathrm{P}<.620$} & \multicolumn{3}{|c|}{ Value: -.019, $\mathrm{P}<. .569$} \\
\hline
\end{tabular}

Table 3 shows the correlation between satisfaction in life and religious belief. In the male category, 53 percent of religious believers and 52 percent of both not religious believers and convinced atheists were highly satisfied. Likewise, in the female category, 55 percent, 60 percent and 51 percent religious believers, not religious believers and convinced atheists respectively showed high satisfaction in their lives. This means that for both males and females more than half of the respondents in every case were highly satisfied regardless of their religious affiliation. The Spearman correlation values of -.017 for males and -.019 for females also show that 
there is a negative correlation and even that the relationship is not significant at a 0.05 level. These statistics strongly suggest that satisfaction in life does not differ by religion for either males or females.

\subsubsection{Employment}

Data in table 4 present the association between satisfaction in life and employment status. Among males, 57 per cent of those who were employed, which compares to more than the same percentage (58 percent) of unemployed females, were highly satisfied.

Table 4: Life Satisfaction by Employment and Gender

\begin{tabular}{|c|c|c|c|c|}
\hline \multirow[t]{4}{*}{ Level of Satisfaction } & \multicolumn{4}{|c|}{ Employed } \\
\hline & \multicolumn{4}{|l|}{ Gender } \\
\hline & \multicolumn{2}{|c|}{ Male } & \multicolumn{2}{|c|}{ Female } \\
\hline & Yes & No & Yes & No \\
\hline High Satisfaction & 330 & 124 & 241 & 285 \\
\hline$\%$ & 56.5 & 43.1 & 55.7 & 57.8 \\
\hline Medium Satisfaction & 222 & 133 & 171 & 171 \\
\hline$\%$ & 38.0 & 46.2 & 39.5 & 34.7 \\
\hline Low Satisfaction & 32 & 31 & 21 & 37 \\
\hline$\%$ & 5.5 & 10.8 & 4.8 & 7.5 \\
\hline Total & 584 & 288 & 433 & 493 \\
\hline$\%$ & 100.0 & 100.0 & 100.0 & 100.0 \\
\hline Pearson Chi-Square & \multicolumn{2}{|c|}{ Value: $17.318, \mathrm{DF}=2, \mathrm{P}<. .000$} & \multicolumn{2}{|c|}{ Value: $4.224, \mathrm{DF}=2, \mathrm{P}<. .121$} \\
\hline
\end{tabular}

The value of chi square for males is 17.318 with 2 Degrees of Freedom (DF) and $\mathrm{P}<.01$. This value is highly significant $(\mathrm{P}<.000)$, indicating that satisfaction in life for males varies in accordance with employment status. Contrarily, the chi square value for females (4.224) is still lower than the tabulated value and the $\mathrm{P}<.121$ is still higher than 0.05 . This indicates that satisfaction in life for females does not vary according to employment status. 


\subsubsection{Marriage}

Table 5 shows the association between satisfaction in life and marital status by gender. Marital status is divided into four categories to include married, widowed, divorced and never married. Data in the above table show that 58 per cent of married males were highly satisfied in their lives whereas fewer than 6 per cent had low satisfaction in that category. In the same way, for married females, the satisfaction rate was higher at 62 per cent than for non-married female respondents and only 4 percent reported low satisfaction. Additionally, high satisfaction among widows was commoner (37\%) than among widowers (35\%). Again, 70 per cent of never married females had high satisfaction levels in their lives whereas 50 percent, fully 20 percent lower, in the same category of males were highly satisfied.

Table 5: Life Satisfaction by Marital Status and Gender

\begin{tabular}{|c|c|c|c|c|c|c|c|c|}
\hline \multirow{4}{*}{$\begin{array}{l}\text { Level of } \\
\text { Satisfaction }\end{array}$} & \multicolumn{8}{|c|}{ Marital Status } \\
\hline & \multicolumn{8}{|l|}{ Gender } \\
\hline & \multicolumn{4}{|c|}{ Male } & \multicolumn{4}{|c|}{ Female } \\
\hline & Married & Widower & Divorced & $\begin{array}{c}\text { Never } \\
\text { Married }\end{array}$ & Married & Widowed & Divorced & $\begin{array}{c}\text { Never } \\
\text { Married }\end{array}$ \\
\hline $\begin{array}{l}\text { High } \\
\text { Satisfaction }\end{array}$ & 252 & 17 & 46 & 141 & 257 & 62 & 62 & 145 \\
\hline$\%$ & 57.8 & 35.4 & 43.0 & 50.4 & 62.2 & 36.7 & 44.9 & 70.4 \\
\hline $\begin{array}{l}\text { Medium } \\
\text { Satisfaction }\end{array}$ & 160 & 25 & 49 & 119 & 140 & 83 & 61 & 57 \\
\hline$\%$ & 36.7 & 52.1 & 45.8 & 42.5 & 33.9 & 49.1 & 44.2 & 27.7 \\
\hline $\begin{array}{l}\text { Low } \\
\text { Satisfaction }\end{array}$ & 24 & 6 & 12 & 20 & 16 & 24 & 15 & 4 \\
\hline$\%$ & 5.5 & 12.5 & 11.2 & 7.1 & 3.9 & 14.2 & 10.9 & 1.9 \\
\hline Total & 436 & 48 & 107 & 280 & 413 & 169 & 138 & 206 \\
\hline$\%$ & 100.0 & 100.0 & 100.0 & 100.0 & 100.0 & 100.0 & 100.0 & 100.0 \\
\hline $\begin{array}{l}\text { Pearson Chi- } \\
\text { Square }\end{array}$ & \multicolumn{4}{|c|}{ Value: $17.336, \mathrm{DF}=6, \mathrm{P}<.008$} & \multicolumn{4}{|c|}{ Value: $69.947, \mathrm{DF}=6, \mathrm{P}<.000$} \\
\hline
\end{tabular}

The value of chi square for males is 17.336 which is greater than the tabulated value of 16.81 at 6 degrees of freedom and $\mathrm{P}<.01$. This value is 
significant $(\mathrm{P}<.008)$, indicating that satisfaction in life for males varies in accordance with marital status. Again, the chi square value for females (69.947) is still greater than the tabulated value at 6 degrees of freedom at $P$ $<.01$. Besides this, $\mathrm{P}<.000$ for the female category indicates that relationship between the variables of satisfaction in life and marital status are highly significant. So it is clear that life satisfaction varies by marital status for both males and females but the tendency is greater in females than in males.

\subsubsection{Importance of Family}

Table 6 shows the correlation between satisfaction in life and importance of family by gender. Importance of family is divided into three ranking categories: very important, important and not important. Fifty-six per cent of males who thought family was very important were highly satisfied whereas only 6 percent of the same category reported low satisfaction.

Table 6: Life Satisfaction by Importance of Family and Gender

\begin{tabular}{|c|c|c|c|c|c|c|}
\hline \multirow{4}{*}{$\begin{array}{l}\text { Level of } \\
\text { Satisfaction }\end{array}$} & \multicolumn{6}{|c|}{ Importance of Family } \\
\hline & \multicolumn{6}{|l|}{ Gender } \\
\hline & \multicolumn{3}{|c|}{ Male } & \multicolumn{3}{|c|}{ Female } \\
\hline & $\begin{array}{c}\text { Very } \\
\text { Important }\end{array}$ & Important & $\begin{array}{c}\text { Not } \\
\text { Important }\end{array}$ & $\begin{array}{c}\text { Very } \\
\text { Important }\end{array}$ & Important & $\begin{array}{c}\text { Not } \\
\text { Important }\end{array}$ \\
\hline $\begin{array}{l}\text { High } \\
\text { Satisfaction }\end{array}$ & 348 & 88 & 18 & 461 & 61 & 6 \\
\hline$\%$ & 55.6 & 46.8 & 36.0 & 58.9 & 48.8 & 30.0 \\
\hline $\begin{array}{l}\text { Medium } \\
\text { Satisfaction }\end{array}$ & 241 & 86 & 23 & 280 & 51 & 11 \\
\hline$\%$ & 38.5 & 45.7 & 46.0 & 35.8 & 40.8 & 55.0 \\
\hline $\begin{array}{l}\text { Low } \\
\text { Satisfaction }\end{array}$ & 37 & 14 & 9 & 42 & 13 & 3 \\
\hline$\%$ & 5.9 & 7.4 & 18.0 & 5.4 & 10.4 & 15.0 \\
\hline Total & 626 & 188 & 50 & 783 & 125 & 20 \\
\hline$\%$ & 100.0 & 100.0 & 100.0 & 100.0 & 100.0 & 100.0 \\
\hline $\begin{array}{l}\text { Spearman } \\
\text { Correlation }\end{array}$ & \multicolumn{3}{|c|}{ Value: .112, $\mathrm{P}<.000$} & \multicolumn{3}{|c|}{ Value: .105, $\mathrm{P}<.000$} \\
\hline
\end{tabular}


The same situation was found in females, with high satisfaction in life among 59 percent of those who identified family as very important and only 5 percent reporting low satisfaction. But females who showed medium satisfaction and did not identify the importance of family amounted to 55 per cent, which is 9 per cent higher than males who had similar views about family. The value of the Spearman correlation for males (.112) and females (.105) showed a positive correlation between satisfaction in life and importance of family but the strength was low, the values not being close to 1. Statistically, however, the associations are highly significant at $\mathrm{P}<.000$ for both male and female groups. Comparatively, the associations of male groups are as the Spearman correlation value of .112 is closer to 1 than is the .105 for female.

\subsection{Extrinsic Aspirations}

\subsubsection{Political View}

Table 7: Life Satisfaction by Political View and Gender

\begin{tabular}{|c|c|c|c|c|}
\hline Gender & & & \begin{tabular}{|c|} 
Satisfaction in \\
Life
\end{tabular} & $\begin{array}{l}\text { Political View: } \\
\text { Left-Right }\end{array}$ \\
\hline \multirow{6}{*}{ Male } & \multirow{3}{*}{ Satisfaction in Life } & Pearson Correlation & 1 & $.144^{*}$ \\
\hline & & Sig. (2-tailed) & & .000 \\
\hline & & $\mathrm{N}$ & 875 & 739 \\
\hline & \multirow{3}{*}{ Political View: Left-Right } & Pearson Correlation & $.144^{* *}$ & 1 \\
\hline & & \begin{tabular}{|l|} 
Sig. (2-tailed) \\
\end{tabular} & .000 & \\
\hline & & $\mathrm{N}$ & 739 & 742 \\
\hline \multirow{6}{*}{ Female } & \multirow{3}{*}{ Satisfaction in Life } & Pearson Correlation & 1 & .079 \\
\hline & & Sig. (2-tailed) & & .037 \\
\hline & & $\mathrm{N}$ & 932 & 705 \\
\hline & \multirow{3}{*}{ Political View: Left-Right } & Pearson Correlation & $.079^{*}$ & 1 \\
\hline & & \begin{tabular}{|l|} 
Sig. (2-tailed) \\
\end{tabular} & .037 & \\
\hline & & $\mathrm{N}$ & 705 & 705 \\
\hline \multicolumn{5}{|c|}{ **. Correlation is significant at the 0.01 level (2-tailed). } \\
\hline
\end{tabular}


The independent variable political view left-right is measured on a 10 point scale. This scale implies that those who have the highest ranking are more prone to support the right and have a tendency towards democracy. SPSS Output provides a matrix of the Pearson correlation coefficients for the two variables in two groups, male and females, as shown in Table 7. Each variable is perfectly correlated with itself (obviously) and so Pearson $r=1$ along the diagonal of the table.

The table shows that the variable satisfaction in life, in the male category, is positively correlated with political view: left-right, with a coefficient $r=.144$ which is also significant at $\mathrm{P}<0.01$. In the female category, satisfaction in life is positively correlated with political view: leftright, with a coefficient $r=.079$ which is also significant at $\mathrm{P}<0.05$. Despite there being only a low positive correlation between life satisfaction and political view: left-right for both male and female groups, there does exist a difference in extent of relationship. The Pearson correlation $r$ for males indicates that the variables life satisfaction and political view: leftright have higher associations than in females.

\subsubsection{Democracy}

Table 8 presents the correlation between life satisfaction and satisfaction with democracy and gender. Here variable satisfaction with democracy represents people's attitude to the democratic activities of government. Satisfaction with democracy has been categorized into four rankings: very satisfied, rather, little and not at all. Data shows that the number of people in the Czech Republic very satisfied with their democracy is not very high, and overall high satisfaction in life varies in accordance with gender categories. A substantial portion (93\%) of males who were very satisfied with their democracy had high satisfaction in life 
whereas for females the figure was 86 per cent. Again, 45 per cent among females, compared to 33 per cent among males, of those who were not at all satisfied with democracy expressed high satisfaction in life. Spearman correlation values of .230 (for male) and .145 (for female) indicate a positive correlation between satisfaction in life and satisfaction with democracy though the strength of the relation is not high as neither value is close to 1 . Moreover the relationships between variables for both male and female cases are statistically highly significant $(\mathrm{P}<.000$.) By comparison, the correlation value for males (.230) shows a greater strength of association between satisfaction in life and satisfaction with democracy than in the case of their female counterparts.

Table 8 Satisfaction in Life by Satisfaction with Democracy by Gender

\begin{tabular}{|c|c|c|c|c|c|c|c|c|}
\hline \multirow{4}{*}{$\begin{array}{l}\text { Level of } \\
\text { Satisfaction }\end{array}$} & \multicolumn{8}{|c|}{ Satisfaction with Democracy } \\
\hline & \multicolumn{8}{|l|}{ Gender } \\
\hline & \multicolumn{4}{|c|}{ Male } & \multicolumn{4}{|c|}{ Female } \\
\hline & $\begin{array}{c}\text { Very } \\
\text { Satisfied }\end{array}$ & $\begin{array}{c}\text { Rather } \\
\text { Satisfied }\end{array}$ & $\begin{array}{c}\text { Little } \\
\text { Satisfied }\end{array}$ & $\begin{array}{c}\text { Not at } \\
\text { all }\end{array}$ & $\begin{array}{c}\text { Very } \\
\text { Satisfied }\end{array}$ & $\begin{array}{c}\text { Rather } \\
\text { Satisfied }\end{array}$ & $\begin{array}{c}\text { Little } \\
\text { Satisfied }\end{array}$ & $\begin{array}{c}\text { Not at } \\
\text { all }\end{array}$ \\
\hline $\begin{array}{l}\text { High } \\
\text { Satisfaction }\end{array}$ & 14 & 198 & 190 & 38 & 24 & 201 & 213 & 59 \\
\hline$\%$ & 93.3 & 61.3 & 48.8 & 32.5 & 85.7 & 61.1 & 56.1 & 44.7 \\
\hline $\begin{array}{l}\text { Medium } \\
\text { Satisfaction }\end{array}$ & 1 & 112 & 178 & 53 & 4 & 119 & 138 & 60 \\
\hline$\%$ & 6.7 & 34.7 & 45.8 & 45.3 & 14.3 & 36.2 & 36.3 & 45.5 \\
\hline $\begin{array}{l}\text { Low } \\
\text { Satisfaction }\end{array}$ & 0 & 13 & 21 & 26 & 0 & 9 & 29 & 13 \\
\hline$\%$ & 0.0 & 4.0 & 5.4 & 22.2 & 0.0 & 2.7 & 7.6 & 9.8 \\
\hline Total & 15 & 323 & 389 & 117 & 28 & 329 & 380 & 132 \\
\hline$\%$ & 100.0 & 100.0 & 100.0 & 100.0 & 100.0 & 100.0 & 100.0 & 100.0 \\
\hline $\begin{array}{l}\text { Spearman } \\
\text { Correlation }\end{array}$ & \multicolumn{4}{|c|}{ Value: .230, $\mathrm{P}<.000$} & \multicolumn{4}{|c|}{ Value: .145, $\mathrm{P}<.000$} \\
\hline
\end{tabular}

\section{Discussion}

Table 1 in its results section provides the answer to our first supporting research question about differences in life satisfaction between males and females. Though the difference in overall satisfaction is not 
significant, females in the Czech Republic are more satisfied in their lives. In addition, the answer to this research question is expressed in a discussion of intrinsic and extrinsic aspects.

\subsection{Intrinsic}

The answer to the second of our research questions comes explicitly from the results of intrinsic aspects. This answer includes five areas: age, religion, employment, marriage and importance of family. Satisfaction in life for people in the Czech Republic varies for different age groups. In fact it depends on a variety of factors such as age of youth; job at a particular age, partnership status and so forth. It can be seen from the results that young and middle-aged people are more satisfied in their life than the elderly. It is also critical that young females in the 18-32 age groups were more satisfied in their life than males. In this context Wang (2008) identified lower and the lowest life satisfaction at the ages of 75 and 80 respectively.

As for religion, this is not a significant factor in determining the satisfaction in life of people in the Czech Republic. We may note here a similarity with the study on African American women conducted by Saundra and Hughey (2003). They found no relationship between black women's spirituality and life satisfaction. By contrast, employment is a vital factor in determining satisfaction. My study results indicate that employed males were markedly more satisfied in their life than employed females in the Czech Republic. This situation might be a consequence of females' more dependent status and of a lower degree of concern about employment in their case. This is related to the capability approach that emphasizes how individuals achieve effective performance with their 
resources (Sen 1999). Marriage, as a social status, plays a vital role in influencing satisfaction in life. The data shows that married people had comparatively higher satisfaction levels than the widowed and divorced, with married females more likely to express their satisfaction in life than married males. Relevantly, Kousha and Mohseni (1997) identified Iranian women's life satisfaction and found more life satisfaction among married women than unmarried. Finally, importance of family is another factor that influences life satisfaction. Study results suggest that when people think family is very important, their satisfaction in life is high. One previouslymentioned study emphasizes the importance of family in building life satisfaction (Marín and Marín 1991). But it is interesting that there was a closer link between satisfaction in life and attaching high importance to family among males than among females. Overall, this intrinsic aspect is related to the phenomena of self determination theory as it correlates the internal qualities of the individual.

\subsection{Extrinsic}

The third research question about life satisfaction in extrinsic aspects is encountered in connection with political view and democracy. Firstly, political view is an external factor related to life satisfaction as one's ideology is expressed through political views. This ideology is a mindset that constitutes one's expectations. This study results suggest that satisfaction in life is influenced by people's political views and that this is so for both male and female categories. But it is noteworthy, though both males and females hold democratic views in their modern life, males'

tendency towards democracy is comparatively more and their life satisfaction is higher as well, in contrast to their female counterpart. It 
suggests that lower concentration, though it is not substantial, to democracy of female may lessen the life satisfaction. Flavin and Michael (2007) identified political culture as an independent variable for life satisfaction. Secondly, a political variable called democracy influences life satisfaction. The results of the study show that in the Czech Republic the number of 'very satisfied with democracy' responses is lower than that in other categories though the percentage is still substantial. Males are comparatively more satisfied with and appreciative of the democratic system in the Czech Republic and their satisfaction in life is more determined by democracy than is the case for females. Frey and Stutzer (2000) present clear evidence that democracy in itself increases satisfaction. But females’ lower association between life satisfaction and satisfaction with democracy demonstrates that they may not have equal access everywhere as men do.

\section{Conclusion}

Finally, it may be said that life satisfaction varies in gender categories and at the level of intrinsic and extrinsic levels. Overall, a mean comparison of the statistics shows that females are more satisfied in their life than males. This may in fact be the outcome of a degree of freedom from work, reminding us of the capability approach and its emphasis on freedom achieving multiple combinations of functionings (Sen 1999: 93).

Intrinsic aspiration includes age, religion, marriage, employment and importance of family. The results of this study show that satisfaction in life is correlated in every category except religion. Critically, satisfaction in life in females is more related to age and marriage whereas for their male 
counterparts, it is more associated with employment and importance of family for this same aspiration.

Extrinsic aspiration includes political view and democracy, these being outside of individual life. Here it is in males that there is a stronger correlation between satisfaction in life and political view and democracy. Where political view is concerned, a greater centre-right concentration among males expresses the democratic tendency more strongly, whereas females have more leftist ideas.

It is said that both males and females have an association between satisfaction in life and intrinsic and extrinsic aspirations. Critically, females' satisfaction in life is only higher in correlation with some intrinsic aspirations whereas males have higher associations in both intrinsic and extrinsic aspirations.

This quantitative study has significance if we wish to achieve gender balance by ensuring life satisfaction for both men and women in every area. Besides this, this approach opens up a new route to studying satisfaction in life by comparing males with females in two essential aspects - intrinsic and extrinsic aspirations. To improve this research area in the future, my suggestion would be to widen the research to include aspirations such as a person's involvement with welfare, culture and so forth.

\section{References}

Beutell, N. 2006. “Life Satisfaction, a Sloan Network Encyclopedia Entry.” Journal of Sloan Work and Family 2(3):1125-27.

Chipperfield, J.G. and B. Havens. 2001. "Gender Differences in the Relationships between Marital Status Transitions and Life Satisfaction in Later Life.” Journal of Marriage and the Family 12(3):176-86.

Flavin, Patrick and Michael J. Keane. 2007. "Life Satisfaction and Political Participation: 
Evidence from the United States.” Journal of Happiness Studies 1(2):1-28.

Frey, Bruno and Alois Stutzer. 2000. “Happiness Prospers in Democracy.” Journal of

Happiness Studies 1(1):79-102.

Kasser, Tim and Richard M. Ryan. 1996. "Further Examining the American Dream:

Differential Correlates of Intrinsic and Extrinsic Goals.” Personality and Social

Psychology Bulletin 22(3):280-87.

Kousha, Mahnaz and Navid Mohseni. 1997. "Predictors of Life Satisfaction among Urban Iranian Women: An Exploratory Analysis.” Journal of Social Indicators Research 40(3):329-57.

Marín, G. and BV. Marín. 1991. Research with Hispanic Populations. Applied Research Methods Series. Thousand Oaks, CA: Sage.

Saundra, H.S. and A.W. Hughey. 2003. “African American Women at Mid-life: The Relationship between Spirituality and Life Satisfaction.” Journal of African American Women 18(2):133-47.

Sen, Amartya K. 1992. Inequality Reexamined. Oxford, UK: Oxford University Press.

---. 1999. Development as Freedom. New York: Anchor Books.

Shin, D. C. and D. M. Johnson. 1978. “Avowed Happiness as the Overall Assessment of the Quality of Life.” Social Indicators Research 5:475-92.

Wang, Chia-Chun. 2008. Leisure Participation, Leisure Motivation and Life Satisfaction for Elders in Public. Ph.D. Dissertation, School of Graduate Studies, University of Incarnate Word, (Publication No. 3313797).

Wikipedia. 2013. “Life Satisfaction.” in Wikipedia Online: The Free Encyclopedia. Available: http://en.wikipedia.org/wiki/Life_satisfaction [Accessed 2014, May $16]$. 